\title{
Implications of Communication in Company Management - Thematic Analysis Based on Interview
}

\author{
Daniela Nechita, Florina Oana Vîrlănuţă, Carmen Opriţ-Maftei \\ Associate Professor Daniela Nechita, Ph.D., Department of Economics, Faculty of Economics and Business \\ Administration, "Dunărea de Jos" University of Galaţi, Romania, \\ email: dananechita2002@yahoo.it \\ Associate Professor Florina Oana Vîrlănuţă, Ph.D. Department of Economics, Faculty of Economics and \\ Business Administration, "Dunărea de Jos" University of Galaţi, Romania, \\ email: florinaoana27@yahoo.com \\ Associate Professor Carmen Opriţ-Maftei, Ph.D. English Department, Faculty of Letters, "Dunărea de Jos" \\ University of Galaţi, Romania. \\ email: c_maftei@yahoo.com
}

\begin{abstract}
Communication is of the utmost importance in management, since understanding employees' issues, social relationship sustainability, manager's capacity of motivating and leading subordinates and the relationships with the external environment in which the company operates, rely heavily on the quality of communication. Basically the communication issue is in management the issue of circulating ideas and solutions oriented towards achieving the company's objectives through open channels of communication both inside and outside the company. The paper shows that the manager's contribution goes beyond the economic side, equally important being the social efficiency revealed by aspects that cannot be quantified directly but with multiple consequences upon all factors involved in a company's activities and especially upon the human factor.
\end{abstract}

\section{Keywords}

Communication; personal relationships; social efficiency; managerial capacity.

\section{Council for Innovative Research}

Peer Review Research Publishing System

Journal: International Journal of Management \& Information Technology

\author{
Vol.3, No.3 \\ editor@cirworld.com \\ www.cirworld.com, member.cirworld.com
}




\section{INTRODUCTION}

Communication is a common aspect of our life. Our existence is touched by more or less fragmented communication, more or less efficient. Thus each and every individual consciously develops his or her protection system against the risk of being influenced, curious, or attached displayed within groups. Interpersonal relationships are indestructible connected to the communication process. Their marriage is so strong that it is believed that we cannot live without communication and that the simple presence of an interlocutor becomes the condition sine qua non condition that triggers the act of communication. The latest studies show that silence itself can be regarded as a multiple response. Added to the incredible potential of direct relationships, the means of communication generally enhance and multiply the individual's possibilities of communication. The communication phenomenon, the communication competence in general is revealed at the intersection of two levels: the psychological level oriented decisively towards the temperamental particularities and the psychosocial level determined by a certain ability to interact.

The psychological component is mainly responsible for the individual behaviour, for his or her options, orientations and attitudes and guarantees a certain consistency of behaviour, determined by temperamental peculiarities, by a certain way of acting and reacting. The psychosocial component is revealed by the individual ability to interact with others, providing the basic requirement of a communication, namely the interlocutor. The communication competence switches to interpersonal relationships or to or group level as sociability and acquires a powerful persuasive force in a public relationship due to its interactive functions.

Managerial communication, in order to be efficient within the company, must be supported by cooperation and involvement of all employees. This type of communication requires a superior understanding of the meaning of environmental development in which the company operates as well as the implications of these changes on the company, so that the organization can identify with the strategic objectives, thus achieving a genuine social partnership.

\section{LITERATURE REVIEW}

Today's modern society is excessively formalized in order to adapt to the increasingly intrusive social requirements. As a consequence, the modern man is thus forced to lead a more social than personal existence, which can survive only by undermining, most often the latter. Typically, relationships are characterized by purposes, actions and rules. For this reason, studies analyzing how people appreciate the importance of the list of purposes for different relationships, discovered that people pursue three aspects in relationships: their own physical well-being, social acceptance and situation- and task specific-related purposes.

A broad field of research is provided by the analysis of what is constant and what is variable in human relations, of the differences that occur in relationships involving different social classes and groups, cultures and age and sex characteristics. Analyzing how these aspects may influence the dynamics of relationships can explain numerous aspects of the individual involvement in the social plan, his or her openness or resistance to change.

People organize themselves in groups and stick together due to their shared beliefs, opinions and prejudice that are common to group members. Thus they all aspire to speak, to dialogue in a world shaken by multimedia communication but which paradoxically establishes an impersonal silence, everything happens as if we didn't want to transmit the main point. (Raoul Pantanella).

A guideline of the theory of communication due to the vast theoretical base was formulated by Jürgen Habermas (The Theory of Communicative Action, German: Theorie des kommunikativen Handelns), the leading representative of the Frankfurt School's second generation. By interpreting the theories of sociology initiated by Talcott Parsons, Habermas developed in 1981 his sociology of "communicative action". Action and interaction are no longer considered only as producing effects, but they can be regarded as symbolic exchanges and contexts associated with language. Attitudes and opinions that accompany action can not grasp the reality by themselves. Critical sociology should study the interaction networks in a society made up of communicational relationships, "opposite subjects brought together by communication." Another guideline in the literature review is represented by the theoretical position of the Palo Alto school, which considers communication as an integrated social phenomenon, trying through "grammar" (or "logical communication") to build a bridge between relational aspects and organizational ones, between the mechanisms that regulate the inter-individual relationships and those that regulate social relationships. A precursor of the new communication model developed by the Palo Alto school was Gregory Bateson - the British anthropologist and ecologist who was initially as a biologist. His book Steps to an Ecology of Mind, tried to introduce an organicist view of communication.

Paul Grice's theory (Logic and Conversation, 1975), intended to highlight the principles that arise from any form of communication, based on the a priori context of its formulation as a result of conversation analysis, of investigating its conditions of existence and adequacy. Grice attempted to compile as conversational maxims, the rules that the actors engaging in a dialogue must comply with. Thus conversational maxims will therefore have to deal directly with the "general discourse features ". These maxims are formulated starting from a general principle, namely the principle of cooperation: "Make your conversational contribution such as it is required, at the stage at which it occurs, by the accepted purpose or direction of the talk exchange in which you are engaged". Grice's conversational maxims arise from the cooperative principle; these categories thus become conditions for the "implicit" present of any form of communication that should be universally applied not to violate the principle of cooperation.

A different approach is provided by Mihai Dinu, in his book Communication (1999) in which he considers religion as a form of communication "do not believe in God but believe in the possibility of communicating with Him". Based on this assessment, Noica believes that this type of knowledge is characterized by certain obvious limits that are specific to verbal communication. 
Groups tend to generate not only norms and relations based on power, but also prestige systems. (Gheorghe Anca Mateescu Laura, Interpersonal Communication). The first attempt of the Romanian managerial literature to highlight the link between emotional behaviour, emotional climate and organizational and individual performance was achieved in 2005 by Rodica Cândea and Dan Cândea in Emotional skills and the success in management. The authors consider that the main condition of survival of any organization is the ability to adapt to changes that occur in its operating environment, and this can be achieved only through intensive and effective communication.

\section{RESEARCH METHODS}

Data collection is an important part of any type of research study. Therefore the interview is one of the most efficient methods of data collection, as it provides reliable, complete and appropriate information. Moreover, as a tool of observation, the interview complies with the scientific methods imported from exact sciences. The interview involves numerous variables that influence what is said: the research context which limits the space of discourse, words and attitude of the interviewee as well as the social relationship between the two interlocutors. In order to ensure the relevance and quality of information, three major aspects of the interaction must be taken into account, i.e. the topic of conversation or study, the interpersonal context and social conditions of interaction. The interview is a particular type of communication and is efficient as it conveys what people think. This is one of the main reasons for which this method of research was taken into consideration for the present study.

The present study focused on a company that operates in port management. Nevertheless the methods we approached can be extended to some other companies, regardless of their field of activity. The grid questions was developed in an attempt to highlight the interdependence between internal communication and marketing communications in order to determine the impact of these two elements of the communication process upon the image of the company. Thus, starting from issues concerning the current position of the company and form the way in which they communicate and manage their image, we tried using the questions included in the interview guide, answers that enable the analysis of activities of promotion and communication and setting effects, as well as of the implications they generate upon the analyzed company. The grid interview used to collect the data required for the analysis was structured on two variables: the communication process and the activity of promotion in order to determine the current position and future directions of the company from its employees' point of view. The interview guide that was delivered to employees was structured as follows:

\section{Interview Guide}

- What does the company you work for do? In a few words describe the type of product/service that you produce/provide and the customers/clients/departments that depend on your department.

- Speak about the activities of the company you work for - main objectives that are pursued. What concrete activities do you do in order to achieve those objectives?

- Which is your company's current position form the economic perspective (company's position towards other companies, mutual relations etc.) the technologic perspective (technical and technological level of the company), hierarchic perspective (who is your superior, who decides what you should do, etc.) and social perspective (what is the status of the employee in your company, how attractive are the company's workplaces etc.)

- Which are the strengths of your company (advantages etc.) and weaknesses (difficulties, disadvantages); opportunities (development perspectives) and treats (barriers or hindrances that may occur).

- Why and how does a company communicate?

- What is communication important in your opinion?

- A company's image is created, built and maintained. Do you consider communication a leading factor in achieving and promoting the image of your company? (Which are the possible ways to communicate? How do we engage in internal and external communication? Can you mention some consequences generated by effective internal communication?

- Do you think that the communication process and managing the company's image are generated by the need for business? What is your opinion in this regard?

- In your opinion, what kind of relationships is there between the promoting activities (of the company, its range of services, etc.) and managerial communication?

- Does your company promote a certain type of organizational culture? Which is it? Is organizational culture an important tool that can be used by company management in order to maximize its performance? In your opinion do you fit into your company's system of values, beliefs and traditions?

- How do you perceive communication in crisis situations? (How does your company handle crisis situations? For instance conflicts, technological incidents, natural disasters, etc.) How does your company communicate in these situations?

- How important is promotion to an organization? (Which is your opinion regarding promotional activity advertising, sales promotion, public relations, promotional events, sales force within the current economic context? Which are the objectives related to the promotional activity that are pursued by the company? Are we speaking about institutional communication - in order to promote the company's image or is it based on the company's range of services? Or is it related to positioning services? Which is the image the company provides to its clients? Does your company pursue as main objective the turnover increase? Which are the other objectives your company aim at achieving through the promotional activity it carries out? Which aspects are the most important? The individual consumers, industrial users, intermediaries, or those related to promotion through advertising, promoting sales and sales force or promotional events. 
- Has your company purchased consulting services in the last $\mathbf{5}$ years? (Personnel selection, organizational climate analysis, training courses, qualification, public issues, services regarding the positions the company should adopt or those related to promoting its image etc.) When? What type of service? Provided by whom? With what results?

- What is your opinion on your company's development? (in an optimistic or pessimistic perspective?)

- If you have any further comments you wish to make (issues you are concerned with and have not been tackled, suggestions, useful tips etc.) please feel free to write them here.

Scientific research in management and marketing is characterized among other features by its aim to contribute to the knowledge and understanding of the behaviour of economic agents, mainly to guide their economic activities towards meeting the increasingly demanding requirements of market. The interview guide we suggested intended to identify and analyze the factors with important implications in a company's communication. The information thus collected can be used to formulate management recommendations for elaborating long- term sustainable development policies.

For a company that is undergoing a restructuring process of its socio-economic systems, characterized by constant change, the development of the relational skills becomes a major challenge. Relationships can be compared to games to a certain extent, pursuing goals and including certain rules which define the roles that the persons engaged in a relationship must perform.

Studies analyzing the praxiology of communication provide answers to many questions about the communication process. In this respect our approach is an attempt to outline the general ways in which a company communicates internally and externally. Moreover we also developed a psycho test that involves 40 questions on issues of communication and organizational aspects. It was mainly designed to determine the ability of employees to engage in relationships and also to emphasize the importance of these factors on the proper functioning of the company as a whole.

In order to interpret the results of the psycho test, we suggested the following structure evaluation. The answers thus collected are compared with two grids for communication skills and organizational skills.

Table 1. Assessing communication skills and organizational skills

\begin{tabular}{|c|c|c|c|}
\hline \multicolumn{2}{|c|}{ Communication Skills } & \multicolumn{2}{c|}{ Organizational Skills } \\
\hline $1-$ yes & $22-$ yes & $2-$ yes & $19-$ yes \\
\hline $3-$ yes & $24-$ yes & $4-$ yes & $23-$ no \\
\hline $10-$ yes & $25-$ no & $5-$ no & $26-$ yes \\
\hline $11-$ yes & $31-$ yes & $6-$ no & $27-$ no \\
\hline $13-$ yes & $34-$ yes & $7-$ yes & $28-$ no \\
\hline $14-$ no & $35-$ no & $8-$ no & $29-$ no \\
\hline $16-$ yes & $36-$ yes & $9-$ no & $30-$ no \\
\hline $17-$ no & $37-$ yes & $12-$ no & $32-$ no \\
\hline $20-$ yes & $38-$ yes & $15-$ yes & $33-$ yes \\
\hline $21-$ yes & $40-$ yes & $18-$ yes & $39-$ no \\
\hline
\end{tabular}

All answers that comply with the grid are countered for each section of the test. The coefficient of assessment for the communication skills and the coefficient of assessment is for the organizational skills are calculated according to the following formula:

where:

$$
\mathrm{C}=0,05 \times \mathrm{N}
$$

C - coefficient of evaluation $(0<\mathrm{C}<1)$;

$\mathrm{N}$ - number of correct answers (of compliance with the grid).

Table 2. Grid for assessing the results of the psychological testing

\begin{tabular}{|c|c|}
\hline \multicolumn{2}{|c|}{ Communication Skills } \\
\hline $\begin{array}{c}\text { Coefficient of assessment } \\
\text { for the communication } \\
\text { skills }\end{array}$ & $\begin{array}{c}\text { Level of } \\
\text { communication }\end{array}$ \\
\hline $0,10-0,45$ & Low \\
\hline $0,46-0,55$ & Below medium \\
\hline $0,56-0,65$ & Medium \\
\hline $0,66-0,75$ & High \\
\hline $0,76-1$ & Very high \\
\hline
\end{tabular}

\begin{tabular}{|c|c|}
\hline \multicolumn{2}{|c|}{ Organizational Skills } \\
\hline $\begin{array}{c}\text { Coefficient of assessment } \\
\text { of the organizational skills }\end{array}$ & $\begin{array}{c}\text { Level of } \\
\text { organizational } \\
\text { skills }\end{array}$ \\
\hline $0,20-0,55$ & Low \\
\hline $0,56-0,65$ & below medium \\
\hline $0,66-0,70$ & Medium \\
\hline $0,71-0,80$ & high \\
\hline $0,81-1$ & Very high \\
\hline
\end{tabular}

Intuitively, we can expect a group to perform better than a single individual. Actually groups regardless of their structure are not always superior to individuals. The group that was analyzed was characterized by the nature of interactions between its members and sometimes the best solution to a problem can be lost between these interactions.

Table 3. How to interpret the psycho test

Interpreting the results of the psycho test

\begin{tabular}{|l|l|l|l|l|l|l|}
\hline \multicolumn{9}{|c|}{ No. } \\
$\begin{array}{c}\text { No. } \\
\text { questionnaire }\end{array}$ & $\mathbf{N}_{\mathbf{c}}$ & $\mathbf{N}_{\mathbf{o}}$ & $\mathbf{N c}_{\mathbf{c}}$ & $\mathbf{N c}_{\mathbf{o}}$ & $\begin{array}{c}\text { Level of } \\
\text { communication }\end{array}$ & Level of organizational skills \\
\hline 1. & & & & & & \\
\hline 2. & & & & & & \\
\hline 3. & & & & & & \\
\hline$\ldots \ldots$ & & & & & & \\
\hline $\mathrm{n}$ & & & & & & \\
\hline
\end{tabular}


where:

$\mathrm{N}_{\mathrm{c}}$ - number of answers that comply with the assessment grid for establishing the communication skills $\mathrm{N}_{\mathrm{o}}$ - number of answers that comply with the assessment grid for establishing the organizational skills $\mathrm{Nc}_{c}-$ coefficient of evaluation of communication skills $\left(\mathrm{Nc}_{\mathrm{c}}=0,05 \times \mathrm{N}_{\mathrm{c}}\right)$

$\mathrm{Nc}_{\circ}-$ coefficient of evaluation of organizational skills $\left(\mathrm{Nc}_{\circ}=0,05 \times \mathrm{N}_{\circ}\right)$

Interpreting the psycho tests results can result in high or higher level of both organizational skills and communication skills as well as of the respondents that are employees of the company. Even though those individuals' self-assessment was realistic and were able to manage their own resources efficiently, their professional development will be subject to the type of organization they work for, to the current economic conditions and to other factors.

\section{RESULTS}

The conducted study based on the interview guide within the company revealed the following aspects that can be related to any other company:

- the company's employees are well-informed, they are familiar with the activities of the company, its partners, and the main issues their company is facing in the current economic context;

- employees believe that communication, regardless of the level it is achieved, is a leading factor in the development and promotion of the image of their company;

- the current position of the company, its success in business - multidimensional phenomenon - involves a series of social aspects: public character, values promoted by the entire society or by a certain social group at a certain time and also psychological aspects (skills, attitudes) as well as adopting a code of conduct; all these aspects being generated by the need for business identity and importance of maintaining and enhancing the company's image locally and nationally;

- employees consider the promoting activities carried out especially in the current economic context as being of the utmost importance for the efficient development of the company and for the improvement of its economic and social performance;

- the company's senior management is aware of the important role promotion plays for the organization, its economic effects and implications upon the company's image and prestige;

- to succeed, the company must make a special effort in order to make optimum use of the material and human resources, pursue the achievement of these activities in time and establish how to monitor and assess the obtained results;

- in order to achieve its most important objective - the client - who is after all "its business" , the company must be aware that one of the most practical tools it can use is promotion and in this respect, influencing the clients behaviour is an issue of effective communication.

To conclude, work performance depends on employees' internal variables - age, skills, interests and motivations, system of values, personality traits, experience. It also depends on external variables, related to the physical and environmental conditions - working space, equipment, methods of work organization, as well as on organizational and social variables the company's type of organization and policy, social environment, etc. Thus communication both internally and externally that is conducted effectively and organized as well as the current and future development programs of the company must be based on understanding the phenomena subordinated to organizational culture. In this regard, senior management should not only perceive these phenomena, but should be able to know measures to take in order to achieve the company's goals.

On the other hand, by promoting an efficient management the company may engage in efficient marketing activities that could enhance its position on the market.

The psycho test helped us diagnose the company's employees' attitudes towards success or failure in terms of the organizational and communicational skills. We discovered that there are people willing to succeed, characterized by perseverance, dynamism and the need of achieving their goals at any cost. And if these motivational qualities are accompanied by "tools" such as skills, adequate interaction styles, then the success of the individual or of the group he or she belongs to is thus guaranteed.

Moreover, the company must stimulate individual efficiency and promote a system of values that should mean to each and every employee values to be acquired, goals to be achieved, rewards to be desired, and behaviour patterns to be used. A possible explanation of this aspect might be that in professional life success does not mean only performance itself but it means performance associated to common goals of those who make up the company.

In order to emphasize the importance of achieving an efficient communication in a company, we designed the following descriptive model of communication:

Moreover, we should start from the fact that changes occur both inside and outside the company. Basically the company is not the only organism that can determine its commercial success. Thus clients, business partners, suppliers, competitors, external collaborators, management consulting firms, etc, can provide valuable ideas on the directions of change, aiming at company's development. On the other hand, another aspect should be taken into account, namely that the more powerful a company, the more important it is to the community, a kind of "collective personality" and its image becomes increasingly stronger.

Due to external communication the management achieves a perspective vision upon its organization, which complies with the external environment, and the company should turn this vision into coherent strategic actions.

Moreover managerial communication pursues the achievement of a climate within the company that generates the feeling of integration and belonging to the organization and that meets the requirements of valuing and understanding of the others. In the same context, proper material rewards should be associated with concerns and activities, including group activities that enhance its cohesion as well as employees' job satisfaction. 
By promoting a certain system of values and broader internal relationships, the company management should know, with flexibility and a certain degree of tolerance, how to anticipatively perceive and understand the times of crisis (by adopting adequate social policies) and employees' expectations.

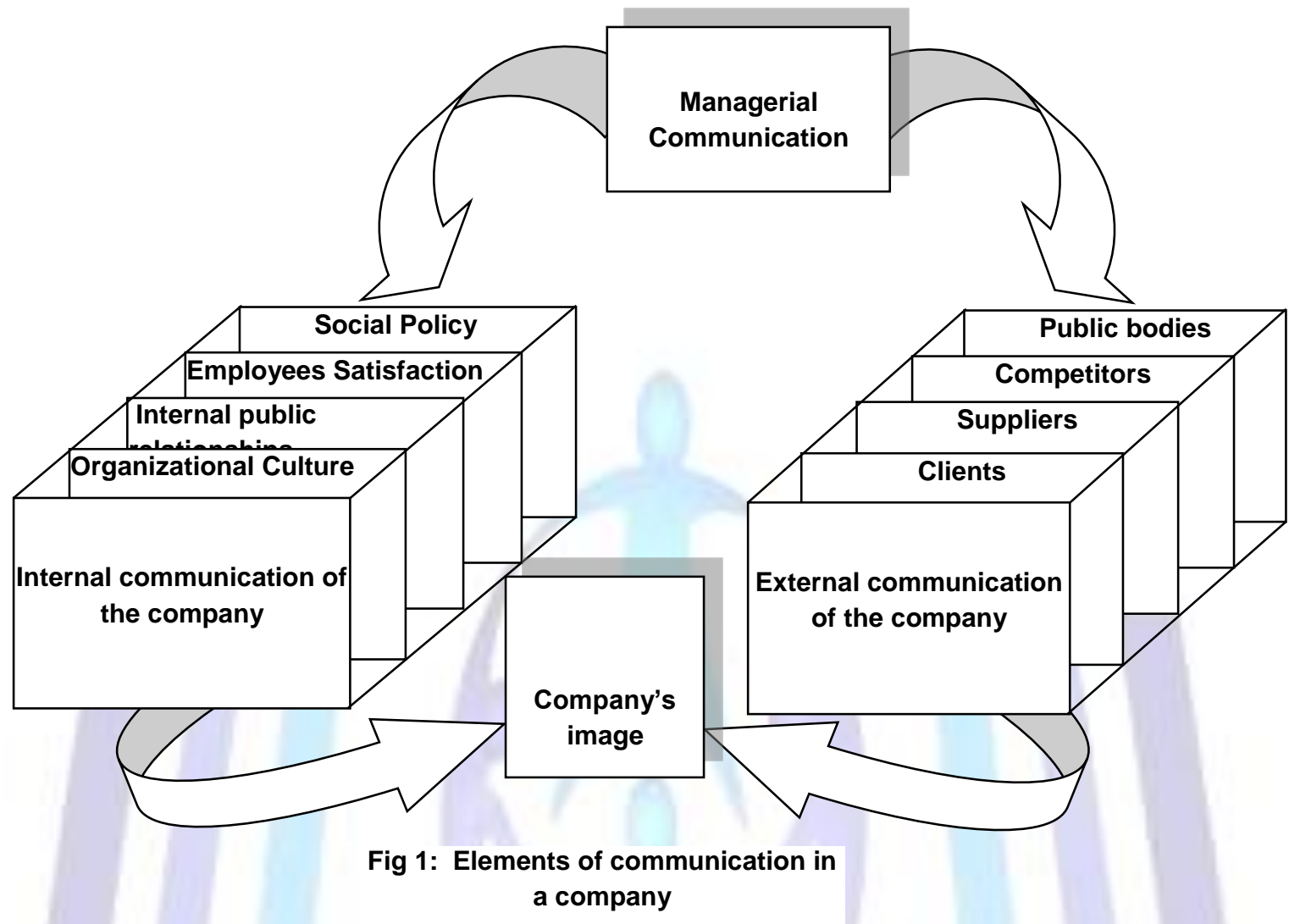

To the "communication above all" leitmotif, the image imperative is added to the individual, businessperson and the company.

For an effective communication the management should display basic qualities such as:

- management for the future - the company should "possess" a sense of the future and a clear strategic vision, since this aspect implies the existence of a balance between action, rapid solution and innovation;

- $\quad$ existence of a strategic planning - the manager should continuously develop a strategic plan for achieving the competitive advantage;

- organizational culture - employees should be committed to company's values, to its habits and should be willing to take risks in order to achieve them. The key factor in the contemporary competitive world is the development of the strategic entrepreneurial spirit (aspect which requires the existence of autonomy and trust in the values and mission of the company) and creativity management;

- $\quad$ strategic flexibility - any company should be prepared to react in rapidly changing environment, trying to anticipate changes, even if it means to reformulate its strategy or change its organisational culture.

Practice shows that in a dynamic and competitive environment, a company unless is heading towards a well-defined purpose, sooner or later will fail. And stagnation is forbidden. The difference between success and failure lies in the managers' ability to act as strategic leaders and thus to develop a thriving company.

\section{CONCLUSIONS}

In order to achieve certain situational goals, various rules and regulations are created or modified within the company. Groups of individuals are looking for ways to achieve their goals, which will become collective solutions including, the proper coordination of behaviour and the exclusion of others by applying these rules. Without "purchasing" such coordination, these goals will not be achieved especially the group goals. The content of the communication, reflected by the way of thinking, rigor and logical fairness, by mental attitudes is the decision-making factor due to which communication makes sense and is relevant. On the other hand, the non-communication implications at the level of any company are so profound that we can say that man has, among other features of social value, a certain need for objectivity, which despite the multiplicity of contacts and social interactions, may remain unexpressed. It has been demonstrated that the difference between a company's success and failure lies in the managerial ability, in its managers' ability to lead the company towards a well-defined purpose and thus to develop an organization that thrives in all respects. 


\section{REFERENCES}

[1] Zamfirescu, V., 1999, În căutarea sinelui, Editura Trei, Bucureşti.

[2] Scott, B., 1996, Arta negocierilor, Editura Tehnică, Bucureşti.

[3] Maslow, A.H., 1954, Motivation and Personality, Editura Harper.

[4] Argyle, M., 1967, The Psychology of Interpersonal Behaviour, Pelican.

[5] Nechita Daniela, 2004, Eficientizarea activităţii portuare prin strategii moderne de marketing - teză de doctorat, Galaţi.

[6] Candea, R., 1996, Comunicarea managerială, Editura Expert, Bucureşti.

[7] Candea, R., Candea, D., 2005, Competenţe emoţionale şi succesul în management, Editura Economică, Bucureşti.

[8] Ciobanu, I., 1998, Management strategic, Editura Polirom, Iaşi.

[9] Dinu, M., 1997, Comunicarea, Editura Ştiinţifică, Bucureşti.

[10] Papuc, M., 2002, Tehnici promoţionale, Editura Sylvi, Bucureşti.

[11] Revista Psihologia, nr.1-6, 1997, Editura Societatea Ştiinţifică şi Tehnică, Bucureşti.

\section{ABOUT THE AUTHORS}

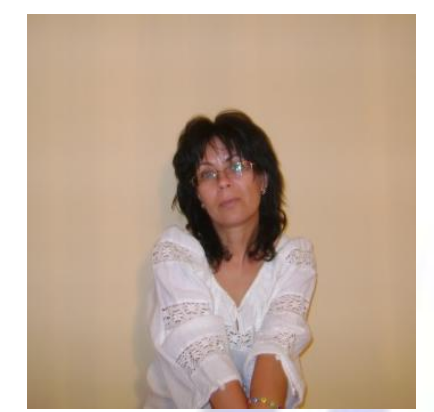

Daniela Nechita
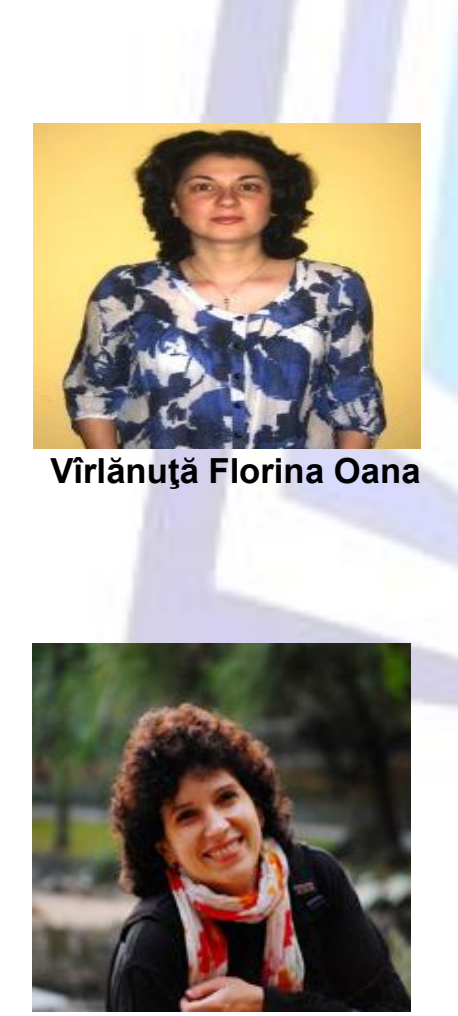

Carmen Oprit-Maftei

\section{Daniela Nechita}

Graduate of the Faculty of Economics and Legal Studies, Galati, Specialization: Marketing, 1995. Ph.D. in Economics, Specialization: Management, "Dunărea de Jos" University of Galati, 2005. Associate Professor Ph.D. at Faculty of Economics and Business Administration, Galati, Department of Economics. Member of World Scientific and Engineering Academy and Society since 2010. Member of CEDIMES since 2009. Author and co-author of 9 books and university courses, articles, studies and scientific papers in the following areas of competence: Microeconomics, Macroeconomics, International Economics, International Efficiency and Competitiveness, Management and Marketing Strategies, International Business Strategies

\section{Vîrlănuţă Florina Oana}

Graduate of the Faculty of Economics, "Dunărea de Jos" University of Galati, Specialization: Economics and Management of Agricultural Food Products, 2001. Ph.D. in Economics, Specialization: Management, Economic Studies Academy, Bucharest, 2009. Associate Professor Ph.D. at Faculty of Economics and Business Administration, Galati, Department of Economics. Member of research centre STRATEC since 2010. Member of CEDIMES since 2009. Author and co-author of 6 books and university courses, more than 30 articles, studies and scientific papers in the following areas of competence: Investments efficiency, Agricultural investment projects, Commercial Insurance, International business financing techniques.

\section{Carmen Oprit-Maftei}

Graduate of the Faculty of Letters, Specialization: English Language and Literature - Romanian Language and Literature, "Dunărea de Jos" University of Galati. PhD in General Linguistics, "Al. I. Cuza" University of Iaşi, 2007. Associate Professor in English at the Department of English, Faculty of Letters, "Dunărea de jos" University of Galaţi. Author and co-author of over thirty scientific papers on ESP and translation studies; co-author of English for Marketing, (2002) Bucureşti: Rentrop \& Straton Publishing House 